\title{
Demagogia fiscal: a contaminação do debate da moralidade tributária do contribuinte no Brasil
}

\author{
Fiscal demagogy: the contamination of the debate of the brazilian taxpayer's morality \\ Paulo Rosenblatt \\ Caio de Souza Leão*
}

\section{Resumo}

A partir do exame do atual cenário do sistema tributário nacional, o presente artigo analisa as contribuições doutrinárias acerca da moralidade tributária, em especial as ideias de Klaus Tipke (2012) para os debates sobre justiça fiscal no Brasil, em suas várias acepções. Assim, discute-se como as iniquidades e contradições do sistema tributário nacional constituem entraves para o adimplemento dos objetivos trazidos pela Constituição Federal de 1988, e como as teorias da moralidade tributária, sobretudo a partir do pensamento de Torres (1998), podem contribuir para o saneamento do sistema tributário brasileiro. As questões centrais debatidas são a regressividade, a isonomia tributária e a capacidade contributiva. O presente artigo pretende demonstrar os recorrentes argumentos de demagogia fiscal, promovidos por grupos de interesse, que afetam a promoção de um Estado Fiscal justo. A hipótese do trabalho é que o discurso demagógico vem contaminando, de modo crescente e duradouro, a moralidade tributária do contribuinte e constitui um entrave à realização de justiça fiscal no país.

Palavras-chave: Tributação. Regressividade. Capacidade contributiva. Moralidade tributária. Demagogia fiscal.

\section{Abstract}

\begin{abstract}
Based on the analysis of the national tax system current situation, this paper analyses the contributions of the tax morality theories, in particular Klaus Tipke's (2012) ideas for the debates about tax justice in Brazil. Therefore, it discusses how the Brazilian tax system's own iniquities and contradictions become obstacles for the country to reach its constitutional objectives from the Federal Constitution of 1988, and how the tax morality theories, especially from Torres's (1998) thought, can contribute to adjusting it to them. The paramount questions considered here are: regressivity, equality and the ability to pay principles. This paper intends to demonstrate the recurrent fiscal demagogy arguments promoted by interest groups that affect the promotion of fiscal fairness. The hypothesis of this article is that the demagogic speech contaminates, in a growing and longstanding way, the taxpayer's morality and constitutes an obstacle for tax justice in Brazil.
\end{abstract}

Keywords: Taxation. Regressivity. Ability to pay. Tax morality. Fiscal demagogy.

\section{Introdução}

Não é novidade o fato de que o Brasil é um dos países mais desiguais do mundo. Em 2017, a organização não-governamental inglesa OXFAM (Oxford Committe for Famine Relief) revelou dados assustadores sobre o país no relatório intitulado $A$ Desigualdade que nos Une. Segundo ele, no Brasil, o $1 \%$ mais rico concentra $48 \%$ de toda a riqueza e, apenas $6 \%$ dos brasileiros possuem o mesmo que os mais de 100 milhões mais pobres (OXFAM, 2017). Em 2018, a mesma OXFAM, no relatório País Estagnado, concluiu que, a partir de 2017, o Brasil deixou de reduzir as desigualdades, processo que vinha ocorrendo desde 2002 (OXFAM, 2018).

A Constituição Federal (CF) de 1988 é oriunda de um contexto de redemocratização do país após mais de 20 anos de ditadura militar, e espelhou uma das grandes preocupações da época: a consagração e efetivação de direitos. Por essa razão, caracteriza-se o texto constitucional pelo primado de princípios ${ }^{1}$ e por ser bastante programática (GRAU, 2014).

(9) (D) PhD em Direito Tributário - Universidade de Londres. Mestrado e graduação em Direito Público pela Faculdade de Direito do Recife (FDR/ UFPE). Professor de Direito Financeiro e Direito Tributário da Universidade Católica de Pernambuco - UNICAP. Procurador do Estado de Pernambuco - PE. Advogado. E-mail: paulo.rosenblatt@unicap.br

(9) Mestrado e graduação em Direito pela Universidade Católica de Pernambuco - UNICAP. Advogado. E-mail: caiosouzaleao@gmail.com

\footnotetext{
“Constitucionalizar um princípio é a forma contemporânea de tentar sacralizar e eternizar um valor considerado imperecível”. (SANCHES, 2010, p. 29).
} 
Dentre os objetivos fundamentais, dispostos no Art. $3^{\circ}$ da Lei Maior, destacam-se a construção de uma sociedade livre, justa e solidária e a necessidade de erradicação da pobreza e da marginalização. O Art. 170, que trata da ordem econômica, igualmente traz a seu bojo também a preocupação com a redução das desigualdades regionais e socioeconômicas. Nesse sentido, Konder Comparato aduz a existência do que chamou de "Estado teocrático", cuja legitimidade reside na capacidade do Estado realizar propósitos predeterminados ante uma orientação finalística da ação dos governos (COMPARATO, 1998).

Passados mais de 30 (trinta) anos, a Constituição brasileira ainda não logrou êxito no que diz respeito a esse crucial desafio. Nesse contexto, cabe indagar qual seria o papel do sistema tributário na superação da pobreza extrema e na redução das desigualdades. E cabe apontar uma latente demagogia fiscal, na sociedade brasileira, que se reflete na captura da lei tributária por grupos de interesse e em um discurso legitimador dessas desigualdades de uma minoria privilegiada.

A tributação é parte da história da civilização e esteve no cerne de diversas rebeliões e revoluções², constituindo, até hoje, elemento central dos debates políticos. Ademais, discuti-la significa "criar um consenso sobre o que deve ser pago a quem e em nome de quais princípios" (PIKETTY, 2014, p. 481). O prenúncio do Estado Fiscal é comumente apontado na Revolução Francesa (SANCHES, 2010). No Brasil, a Revolução Pernambucana de 1817 é um exemplo de reação popular à opressão fiscal imposta pela Coroa Portuguesa (ROSENBLATT, 2018).

No centro da Revolução Francesa de 1789 estava a demanda pela derrubada do feudalismo e dos privilégios e tributos que o mantinham. Mesmo se 'Liberdade, Igualdade e Fraternidade' não fossem, de fato, o cerne da revolução, na Era lluminista ficou evidente que a tributação não apenas deveria refletir a sociedade, mas também possuía a capacidade de transformá-la (MURPHY, 2015, p. 18). ${ }^{3}$

A ideia de justiça tributária está na gênese das grandes revoluções. A tributação, portanto, não apenas reflete a sociedade e seus paradoxos, como também tem a enorme capacidade de transformá-la. Um dos pressupostos adotados pelo presente trabalho é o de que a questão tributária é uma das mais importantes questões políticas e filosóficas, cerne da discussão do papel do Estado, e não mera técnica. E de que, na inexistência da cobrança de tributos, nenhuma sociedade livre e democrática poderá prosperar (PIKETTY, 2014, p. 480).

É importante destacar o caráter polissêmico do conceito de justiça fiscal, como alerta Sanches (2010). O primeiro significado é o de uma avaliação quantitativa da partilha dos encargos tributários entre as várias categorias de contribuintes, particularmente daqueles como rendimentos distintos - o que é uma concepção limitada. O segundo sentido é o da despesa pública, de como o Estado irá empregar seus recursos e de quais serão os privilegiados pela ação governamental. Terceiro, tem-se a distinção entre a justiça fiscal do ponto de vista formal (modo de cobrança dos tributos) e material (conteúdo da tributação, o que inclui o debate entre progressividade e regressividade do sistema). Há um quarto sentido, que é a repartição de encargos tributários entre estruturas locais de governo, sejam estados em uma federação, ou autarquias autônomas em estados unitários. E o quinto é o da capacidade contributiva (cada um deve contribuir de acordo com suas possibilidades) em oposição ao equivocado princípio da equivalência (repartição dos encargos na medida da riqueza de cada contribuinte, mas em proporção com o que obtém em rendimento sob a proteção do Estado) (SANCHES, 2010).

A partir disso, o presente estudo discute a regressividade do sistema tributário nacional, a partir das contribuições da doutrina da moralidade tributária, preocupada com uma tributação mais equânime e capaz de responder às demandas criadas pela Constituição Federal.

\section{0 sistema tributário e os objetivos da constituição de 1988: entre a promoção e a sabotagem}

O Estado realiza a tributação a partir de uma das manifestações de sua soberania: o poder de tributar. Este, somado ao povo e ao território, compõe as características fundamentais do próprio Estado (MACHADO, 2014). Essa manifestação, da soberania estatal, sempre esteve ligada à maneira como a sociedade e a economia de um

Cf. ADAMS, Charels. For good andeEvil: the impact of taxes on the course of civilization. 2a ed. Nova lorque: Madison, 1999.

At the core of the French uprising in 1789 was a demand for the overthrow of feudalism and the privileges and taxs that maintained it. Even if 'Liberté, Égalité, Fraternité' was not, in fact, the cry of that revolution, in the Age of Enlightenment it was held self-evident that taxation not only had to reflect society, but had the capacity to change society.(Tradução dos autores). 
país se estruturam, de modo que a análise da tributação não pode jamais prescindir de um exame da dimensão social do homem (RIBEIRO; GESTEIRO, 2013).

Não por outra razão, a maneira como se tributa revela muitas nuances de uma sociedade, tendo o desenho estatal enquanto influencia na forma como a tributação se realiza. Isso porque o tributo tem como função não apenas o financiamento da máquina pública, mas também a de atuar na realização de objetivos estatais, a exemplo da extrafiscalidade, para atingir determinados fins, principalmente a redistribuição de renda (PISCITELLI, 2011).

No Brasil, a Constituição Federal promulgada em 1988 é peça fundante do Estado Social e Democrático de Direito, pois promoveu a reunião entre elementos liberais - como legalidade, igualdade, segurança jurídica e separação das funções estatais e sociais -, representado pelos direitos oriundos da intervenção nos domínios econômico e social, como as relações de emprego, seguridade, saúde e educação, e políticas distributivas (VALIM, 2020).

No entanto, em que pese a consagração constitucional também de uma série de princípios que denotam um compromisso com a progressividade e com a redução das desigualdades, o sistema tributário é regressivo e muito mais focado em tributos indiretos. E, embora hoje chame muito mais a atenção do público em geral o discurso do tamanho da carga tributária, o grande problema está na sua distribuição:

Mas se o tamanho da carga e sua evolução na última década chamam atenção, sua composição
faz do Brasil um verdadeiro campeão de injustiças tributárias. Os dados de 2015 da Receita Federal
sugerem que os chamados impostos indiretos, que incluem os tributos sobre a produção e o consumo
de bens e serviços, representam, no Brasil, $49,7 \%$ da arrecadação total. Se considerarmos apenas a
carga referente a essa modalidade de impostos, o Brasil passa do vigésimo para o segundo lugar no
ranking de trinta países da OCDE. Tal proporção torna a carga tributária brasileira injusta, na medida
em que todos pagam exatamente a mesma alíquota de imposto sobre o consumo, independentemente
da renda. Ou seja, uma pessoa rica paga muito menos imposto sobre o que consome, em relação à
sua renda, do que uma pessoa pobre, o que caracteriza a regressividade da tributação (CARVALHO,
2018, p. 163).

Assim, vê-se que a tributação brasileira é alicerçada em tributos que consomem muito mais a renda dos pobres do que dos ricos, em razão da centralidade da incidência de impostos e contribuições sobre a circulação de bens e serviços, além da receita bruta (SCAFF, 2008). Tal cenário constitui, portanto, uma iniquidade:

Atualmente, os contribuintes que mais renda têm são mais favorecidos pela tributação indireta. Como possuem mais renda, podem poupar e investir, deixando parcela de sua renda livre da tributação indireta. Os contribuintes com renda menor a utilizam integralmente para o consumo, estando submetidos aos impostos indiretos. Impostos indiretos estão ligados à aristocracia; impostos diretos, à democracia (KIRCHHOF, 2020, p. 534).

É possível afirmar que a forma como a tributação se estrutura no Brasil é contrária, até mesmo, à ideia de República - escolhida como forma de governo desde 1888 - uma vez que ela "tem como foco a ideia de 'antiprivilégio'" (SCAFF, 2008, p. 82). Da forma como se está disposta, os mais aquinhoados possuem evidente privilégio. Os mais pobres são prejudicados por despenderem, relativamente, maiores valores em relação ao que auferem, do que os ricos, os quais, além de consumir, podem poupar e investir (KIRCHHOF, 2020). Aliás, estes são duplamente beneficiados, porque se beneficiam mais das despesas públicas referentes, sobretudo, às instituições voltadas à defesa dos direitos de propriedade. O Estado e suas estruturas jurídicas são uma condição essencial para o funcionamento da economia e da sociedade (HOLMES; SUSTEIN, 1999).

Assim, ao invés de atuar no sentido de promover os objetivos constitucionais, o sistema tributário caminha no sentido de sabotá-los. E, embora não se possa negar a alta carga tributária, é preciso ressaltar que essa se justifica por uma série de escolhas que a sociedade fez acerca serviços públicos, como o Sistema Único de Saúde - SUS - e a educação pública do ensino fundamental ao universitário (CARVALHO, 2018).

Seria inviável sustentar essa rede de proteção social sem receitas tributárias suficientes, ou mesmo enfrentar crises econômicas, especialmente no socorro a instituições financeiras, e sanitárias, como é o caso da pandemia SARS-Covid-19.

4 OCDE - Organização para a Cooperação e Desenvolvimento Econômico. 
A maioria dos países ocidentais apresenta-se como Estados fiscais, ou seja, aqueles que têm nos impostos a principal receita pública (NABAIS, 2008). E, dado o caráter dirigente e principiológico do texto constitucional, por isso denominado "Estado teocrático" (COMPARATO, 1998, p. 43), tem-se que:

(...) os tributos, que são a fonte de recursos do Estado, devem Ihe proporcionar o alcance das metas previstas no preâmbulo da Constituição Federal, observando os fundamentos da República Federativa do Brasil e seus objetivos, nunca se limitando à simples arrecadação de valores, ou seja, os tributos devem cumprir com sua função arrecadatória e com sua função social simultaneamente (RIBEIRO; GESTEIRO, 2013, p. 203).

Como dito, o exercício do poder de tributar é apenas um desdobramento da soberania estatal e, como tudo o que é ínsito às atribuições do Estado, possui índole política (BALEEIRO, 2015). Também por essa razão, ao se estudar a tributação e a política fiscal de um país, sendo esta última definida como "o conjunto de decisões relativas à instituição, organização e aplicação dos impostos em conformidade com os objetivos fixados pelos poderes públicos" (NABAIS, 2008, p. 43), deve-se sempre atentar para os objetivos que os norteiam.

Assim, sendo o poder tributário uma parcela de poder soberano prevista na Constituição, este deve ser exercido no sentido de dar cumprimento aos objetivos constitucionais, quais sejam, edificar uma sociedade justa, livre e solidaria (SANTIAGO, 2018).

Importante observar, nesse contexto, também a relação existente entre as normas tributárias e os direitos fundamentais. Estes, embora imponham restrições à tributação - através de princípios como legalidade e vedação ao confisco, por exemplo -, também encontram naquela, meios para a sua consumação: seja através de instrumentos extrafiscais, seja no uso da arrecadação tributária para financiar políticas públicas (CORREIA NETO, 2017).

\section{A moralidade tributária a partir de Klaus Tipke}

No Brasil durante muito tempo, a moralidade tributária foi estudada muito mais sob a ótica do Art. 37, da CF, ou seja, como uma moralidade da administração tributária. Nesse sentido, poderia esta ser definida da seguinte forma:

[...] é aquela que se vincula não só à obediência estrita da lei que deve ser aplicada, mas também à preocupação de não gerar problemas de nenhuma espécie ao administrado, podendo, inclusive, ser responsabilizado o servidor civilmente, nos termos do Art. $37 \S 1^{\circ}$ da Lei suprema, se ele não agir eticamente. Tal concepção, em matéria tributária, leva evidentemente a uma atuação do Fisco em orientar o contribuinte, mais do que persegui-lo, de exigir os tributos devidos de forma não vexatória, de devolver sem procrastinações as quantias que a título de tributo arrecadou indevidamente, a gerar leis que não sejam confiscatórias, nem políticas tributarias desarrazoadas, assim como não provocar publicidade indevida sobre a vida dos pagadores de tributos, visto que, de rigor, são servidores sustentados pelos contribuintes, a quem devem servir (MARTINS, 1996, p. 20-21).

Contudo, a postura legalista e mais formalista do direito tributário, em profunda crise, deu abertura para a aproximação com outras formas de se observar a relação entre Estado e a sociedade, pautada não apenas na legalidade, mas vista, principalmente, como uma relação entre segurança e justiça, com fundamento nos demais princípios constitucionais (TORRES, 2000). Isto se deu, sobretudo, pela influência crescente da chamada virada kantiana (TORRES, 2005) e do neoconstitucionalismo que o sucedeu.

Nesse contexto, os marcos teóricos sobre o tema aqui endossados são Klaus Tipke, na obra Moral tributária do Estado e dos contribuintes (TIPKE, 2012), Franco Gallo, no livro Las razones del fisco - ética y justicia en los tributos (GALLO, 2011), e Ricardo Lobo Torres, sobretudo no Tratado de Direito Constitucional Financeiro e Tributário (TORRES, 2005). Os três autores trazem visões distintas sobre o tema, mas que podem ser relacionadas de forma profícua e complementar.

Tipke consignou, em síntese, que a moral tributária exige que as leis tributárias devam possuir relação harmônica com a Constituição vigente e com a ética dos direitos fundamentais (TIPKE, 2012). Ele, decerto, foi um precursor do tema da moralidade tributária, voltada à fixação de princípios justos; nesse contexto, concluiu que apenas a capacidade contributiva é adequada a todos os direitos fundamentais das Constituições de Estados de Direito Social, frisando ainda que, entre os países que a adotaram, encontra-se o Brasil (TIPKE, 2012). 
Gallo, por sua vez, entende que, do ponto de vista moral, em um contexto de desigualdade como o atual, os tributos não podem ser vistos apenas como o custo dos direitos, mas sim como um instrumento de redução das desigualdades sociais e desiquilíbrios econômicos através da distribuição dos encargos públicos (GALLO, 2011).

Por seu turno, Ricardo Lobo Torres, grande precursor do tema no Brasil e, influenciado em larga medida por Tipke, levou o debate brasileiro, historicamente preso à ideia de moralidade administrativa, a pensar o tema sob o enfoque da justiça. Para ele, a moral tributária do Estado chega a confundir-se com a própria ideia de justiça fiscal, eis que é dever criar, por parte dos legisladores, um direito tributário justo na distribuição da carga tributária (TORRES, 2005). No entanto, os estudos de Lobo Torres voltavam-se, sobretudo para a moral do contribuinte.

Assim, o presente trabalho tomará a moralidade tributária, sobretudo do ponto de vista do Estado, a qual, de modo sintético, poderia ser conceituada como a utilização do princípio da capacidade contributiva com o desiderato de reduzir desigualdades e desequilíbrios econômicos e, do mesmo modo, concretizar os direitos fundamentais, numa proposta de acomodação dos pensamentos de Tipke, Gallo e Ricardo Lobo Torres.

No Brasil, embora não exista um princípio constitucional explícito da moralidade tributária, esse postulado está inequivocamente presente no ordenamento jurídico. Da conjugação dos já citados Arts. $1^{\circ}, 3^{\circ} \mathrm{e} 170 \mathrm{com} \circ \S^{\circ}$ do Art. 145, todos da Constituição Federal, obtém-se a fórmula que os tributos, sempre que possível, observarão a capacidade contributiva, e que um dos objetivos do Estado é a redução das desigualdades. Logo, o modelo de Estado adotado deve se refletir na sua estrutura tributária (PISCITELLI, 2011).

Assim, a moralidade tributária do Estado tem no princípio da capacidade contributiva o "único princípio fundamental, que é adequado a todos os direitos fundamentais de Constituições de Estados de Direito Social" (TIPKE, 2012, p. 20).

Temos aqui também uma fraqueza conceptual, pois é impossível encontrar um conceito que defina, de uma vez por todas, a capacidade contributiva e que a transforme num metro das boas e más leis fiscais. Nessa fraqueza, porém, reside a força ética da ideia - ou seja, a distribuição dos encargos só pode ser ancorada com solidez no conceito ético de capacidade contributiva. [...] Ora, a adopção do conceito de capacidade contributiva como princípio ordenador da repartição da carga fiscal - uma questão cada vez mais importante quando aumenta o peso da carga fiscal - teve uma consequência decisiva: a concretização dos conceitos gêmeos capacidade contributiva e justiça fiscal - no fundo, a sua geminação (SANCHES, 2010, p. 23).

E, discutir a concretização dos direitos fundamentais, significa também debater a criação de condições para efetivar as promessas constantes da Constituição de 1988, incluindo-se aquelas atinentes ao sistema tributário (CORREIA NETO, 2017).

\subsection{A moralidade do contribuinte}

A relação é tensa entre o Estado e o contribuinte, vez que nem sempre o tributo pago traz o retorno esperado em qualidade de vida (SILVESTRE, 2013), além de existir a inafastável preocupação com ineficiência, desperdício e malversação de recursos públicos, com os riscos de populismo, e com o aumento do intervencionismo na atividade econômica.

Nesse contexto, embora o foco do presente estudo seja a moralidade do Estado, seria contraproducente ignorar que existe uma moralidade do contribuinte, pois é possível apontar uma relação de interdependência entre as moralidades do Estado e do contribuinte. Sob a perspectiva alemã, Tipke elencou 7 (sete) atitudes mentais do contribuinte frente à obrigação tributária, consequências de percepções, ideias, sentimentos e perspectivas (SÁ; MARTINS, 2013).

A primeira classificação é a do homo economicus, o qual norteia suas atitudes em um "individualismo racionalegoístico" (TIPKE, 2012, p. 103) no qual seu único critério é o dinheiro. Ele calcula os riscos de suas atitudes e considera eventuais penalidades, mas não o comove que outros tenham que pagar mais por sua conduta. $\mathrm{O}$ segundo é o barganhista, que sabe da importância do pagamento de tributos, mas vê o Estado como perdulário (TIPKE, 2012). Há também o desgostoso com o Estado. O contribuinte que se mantém alheio por aborrecimento e muitas vezes se abstêm até mesmo das eleições (TIPKE, 2012). O contribuinte liberal, por sua vez, é aquele que vê o tributo como limitador da liberdade, mas algo necessário à manutenção da ordem jurídica, da polícia e do sistema de Justiça (TIPKE, 2012). Para Tipke, há ainda o contribuinte do tipo elusor fiscal legalístico, que 
não costuma realizar juízos morais, e organiza suas condutas de modo a aproveitar as lacunas da lei para pagar o menos possível a título de tributo (TIPKE, 2012). A sexta categoria é a do contribuinte inexperiente; este vive "em estado de inocência", pois não conhece nem entende a legislação tributária e costuma assinar tudo o que seu assessor tributário prepara ou presta suas declarações com muita dificuldade (TIPKE, 2012). E a sétima e última classificação é a do contribuinte sensível à justiça; é aquele que se exsurge por tributos mais baixos e pelo estabelecimento de tributos justos (TIPKE, 2012).

A moral tributária dos contribuintes estudada por Tipke possui como causa a moral adotada pelo Estado. Ele alerta que aquela é evidentemente influenciada por fatores como a imprensa e por best-sellers que costumam reproduzir, em especial, a ideia de uma carga tributária elevada nas mãos de um Estado gastador e incapaz de gerir os recursos públicos com lisura (TIPKE, 2012).

Uma tributação injusta como a brasileira - extremamente complexa, regressiva e focada muito mais no consumo do que na renda, patrimônio e heranças - afeta, evidentemente, a moral tributária dos contribuintes. E, conjugado ao atual descrédito na política e nas instituições, à corrupção e ao mau barateamento dos recursos públicos, apela-se ao argumento de que a carga tributária brasileira seria uma das mais altas do mundo:

Ademais, conforme lição do economista Thomas Piketty, a regressividade, em especial no topo da hierarquia social é capaz de favorecer o crescimento do individualismo e do egoísmo de forma que cabe ao Estado moderno manter a progressividade dos sistemas tributários para que estes não se tornem regressivos (PIKETTY, 2014, p. 484).

Ou seja, a maneira como a tributação é realizada e o retorno do pagamento destes em serviços públicos possui iniludível reflexo na moral do contribuinte.

\subsubsection{Complexidade das normas tributárias, elisão fiscal, moralidade e concretização da justiça tributária}

No clássico da literatura mundial Memórias de Adriano há uma passagem em que o Imperador Adriano, idealizado e romanceado pela escritora Marguerite Yourcenar, reflete acerca de sua crença nas leis:

Devo confessar que acredito pouco nas leis. Quando demasiado duras são transgredidas com razão. Quando muito complicadas, o engenho humano encontra facilmente o meio de escapar por entre as malhas dessa rede frágil e escorregadia (YOURCENAR, 2019, p. 109).

A reflexão acima não é desarrazoada. Hoje é amplamente discutido como a grande complexidade dos sistemas tributários e o alto custo destes abrem espaço para o planejamento tributário - a priori legítimo - e para a sonegação fiscal, além de, também conduzir, por fim, a ineficiência econômica (PASSOS; GUEDES; SILVEIRA, 2018).

Todas essas questões possuem íntima relação com a possibilidade tanto de se atingir maior justiça fiscal quanto de se perseguirem os ditos objetivos da República Federativa do Brasil. Isso porque planejamentos tributários agressivos, a elisão fiscal e a sonegação fiscal constituem expedientes que contribuem para a erosão das bases fiscais estatais, as quais são inafastáveis para a concretização dos objetivos constitucionais.

Nesse sentido, é uma tendência atual o repúdio aos planejamentos tributários agressivos, com esteio nos valores de solidariedade, isonomia e capacidade contributiva, uma aproximação entre direito e moral, inclusive no âmbito internacional, através das 15 ações do projeto BEPS (Base Erositionand Profit Shifting Project) (DE PAULA, 2019).

Não se nega, no entanto, o direito legítimo de se realizar o planejamento tributário e de o contribuinte se organizar de modo a se ter o menor ônus fiscal possível, pois isto faz parte da chamada liberdade negocial (TORRES, 2005). A crítica é justamente aos chamados planejamentos fiscais abusivos os quais distorcem os limites jurídicos, geralmente por meio de abuso de formas jurídicas, o que se aproxima das categorias do homo economicus e do elusor fiscal legalístico, trazidas por Tipke e acima descritas.

No que tange à sonegação fiscal, o argumento de que existe uma justificação moral constitui um enorme cinismo, pois há uma diferença grande entre a sonegação e a chamada resistência legítima a eventual opressão fiscal (TORRES, 2005). 
Assim, trata-se de combater práticas elisivas com base na reaproximação entre direito e moral. A liberdade dos negócios privados não pode justificar o solapamento das normas tributárias (DE PAULA, 2019). Outrossim, há muito o Direito afastou-se da noção de liberdade absoluta propugnada pelo liberalismo clássico (DE PAULA, 2019). Deve-se hoje ter em mente valores como a solidariedade, a qual constitui princípio legitimador de todo o sistema constitucional e que, no campo tributário, denota a cooperação recíproca entre contribuinte - através do adimplemento de seus encargos - e o Estado, por meio da adequada repartição dos ônus e da redistribuição por meio da arrecadação tributária (SANTIAGO, 2019). Nesse sentido, a solidariedade opera no campo da moralidade tributária.

\subsection{Justiça fiscal, justiça social e moral tributária: dependências e desafios}

A justiça fiscal é, certamente, um dos meios mais concretos de se estabelecer a justiça política. E, sendo esta promovida pelo Fisco, deve o seu debate perpassar tanto às instituições políticas quanto às constituições. Desse modo, é preciso ter em mente que esta não se realiza apenas na justiça da cobrança de tributos (justiça tributária),mas abarca também a justiça orçamentária e financeira (TORRES, 2005).

A partir da compreensão que a justiça fiscal possui relação muito próxima com a promoção da justiça social, Franco Gallo aduziu haver absoluta interdependência entre ambas, em contexto no qual o gasto público também deve ser considerado:

[...] a correlação entre a arrecadação tributária e os gastos públicos e sociais [...] é realizada em uma dependência, em termos quantitativos, da justiça fiscal ou da justiça social, realizada em concreto com o instrumento das leis orçamentárias segundo as orientações políticas que sucessivamente prevalecem. Dessas correlações processam também o imposto sobre a política econômica e fiscal, por meio das quais os tributos se consideram altos (ou baixos) não em absoluto, mas em função da qualidade, do retorno e da eficiência do gasto público e social por ele financiados, o que equivale dizer a maior ou menor satisfação que este produz no usuário/contribuinte (GALLO, 2011, p. 135).

Desse modo, o citado autor endossa a ideia de que são os fins econômicos, políticos e sociais que criam as diferenças no momento da repartição da carga tributária, de modo que, para que os tributos integrem uma ordem social justa, devem atender ao princípio da igualdade e vir em um sistema coerente (GALLO, 2011), o que reforça a ideia de que a justiça fiscal perpassa a ideia tributária, mas também orçamentária e financeira (TORRES, 2005).

É o princípio da igualdade e, mais ainda, a capacidade contributiva, que deve nortear um sistema tributário justo, conformador de uma ordem social justa e garantidora da redistribuição de riquezas. No mesmo sentido é a lição de Klaus Tipke sobre o tema:

O princípio da capacidade contributiva é o único princípio fundamental, que é adequado a todos os direitos fundamentais de Constituições de Estados de Direito Social. É também em geral aceito como apropriado. Ninguém deseja ser onerado mais gravosamente do que outros nas mesmas condições econômicas; mas a mesma preocupação deve ele então também reconhecer nos outros (TIPKE, 2012, p. 20-21).

Assim, dada a importância do princípio da capacidade contributiva, é crucial deter-se um pouco mais em seu estudo.

\subsubsection{O papel da isonomia, da capacidade contributiva e do republicanismo na moral tributária do Estado}

A Constituição Federal de 1988, no parágrafo único do Art. 145, dispõe que, sempre que possível, os impostos serão graduados conforme a capacidade econômica do contribuinte, consagrando, portanto, esse princípio, o qual possui suas bases na própria ideia de justiça fiscal (COSTA, 1993) e é frequentemente entendido como uma dotação de sentido material ao princípio da isonomia (COSTA, 1993) ou como uma especificação deste (PISCITELLI, 2011).

\footnotetext{
5 “[...] la correlación entre recaudación tributaria y gastos públicos y sociales [...] se convierte en una dependencia, em términos cuantitativos, de la justicia fiscal respecto de la justicia social, realizada en concreto con el instrumento de las leyes de gasto según las orientaciones políticas que sucecessivamente prevalecen. De estas correlaciones procede también el corolário de política economica y fiscal, por el cual los tributos se consideran altos (o bajos) no em absoluto, sino em función también de la culaidad, de la gratificación y de la eficacia del gasto público y social financiado com ellos que es como decir de la mayor o menor satisfación que éste produce em el usuário contribuyente"(Tradução dos autores).
} 
Em todo caso, algumas considerações devem ser feitas acerca do princípio da igualdade. Ele está disposto na Constituição, como um objetivo da República Federativa do Brasil, em seu Artigo $3^{\circ}$, e como um princípio, no seu Art. $5^{\circ}$, vedando o tratamento desigual perante a lei (proibição de discriminações odiosas ou favorecimentos indevidos). Na seara tributária, sua previsão consta do inciso II, do Art. 150 da Constituição, sendo vedado o tratamento desigual entre contribuintes que estão na mesma situação econômica.

Em todo caso, o princípio da isonomia funciona muito mais como um limite às ações do Estado do que como um objetivo a ser alcançado (PISCITELLI, 2011). Ademais, o Direito não possui a capacidade de tornar todas as pessoas iguais, de modo que, ante as desigualdades existentes, a grande questão é saber quando estas devem ser consideradas para que se dispense tratamento desigual (MACHADO, 1994), visando o tratamento equânime de acordo com as capacidades de cada contribuinte.

Logo, ao se falar em isonomia, esta deve ser entendida em sentido jurídico como a paridade de tratamento, estando sob o mesmo regime fiscal os contribuintes que possuem as mesmas condições e, em sentido econômico, a contribuição em igual medida de acordo com a capacidade contributiva de cada um (UCKMAR, 2002).

Por isso, dado o grande entrelaçamento entre a igualdade e a capacidade contributiva, este é comumente considerado apenas um subprincípio corolário do princípio da igualdade, um parâmetro de comparação entre os contribuintes. Nesse sentido, a capacidade contributiva se coaduna com o princípio da solidariedade, disposto no Art. $3^{\circ}$, inciso I, da Constituição (SCHOUERI, 2017) e é reflexo do Estado Social (TIPKE, 2012).

A aplicação do princípio da capacidade contributiva promove, de um lado, uma tributação distinta para aqueles que possuem condições materiais distintas e, por outro lado, possibilita a redução das desigualdades, pois protege o chamado mínimo existencial (KÖCHE; BUFFON, 2015). Este, por sua vez, é fundamental para que se possa falar em dignidade humana, pois, ao proteger indistintamente a todos, cria condições para uma existência digna (SANTIAGO, 2019), condição para o exercício da liberdade (GARCÍA PELAYO, 2009, apud VALIM, 2020).

\subsubsection{A progressividade como elemento necessário para um sistema tributário justo}

Realizado breve excurso sobre a capacidade contributiva, cumpre demonstrar de que modo essa se relaciona com a ideia de justiça fiscal e, consequentemente, de justiça social. Conforme lição de Klaus Tipke, tributação justa é a que se funda sobre o princípio da capacidade contributiva, o único capaz de se harmonizar com os direitos fundamentais (TIPKE, 2012), sendo a justiça fiscal o caminho efetivo para a justiça distributiva (TORRES, 2005).

Na mesma esteira está a ideia de tributação progressiva; embora sejam conceitos distintos, ambos se pautam na mesma ideia de justiça. A progressividade é instrumento bastante caro à ideia de justiça distributiva, pois visa justamente garantir a distribuição justa da carga tributária (SCHOUERI, 2017), sendo instrumento basilar no desenvolvimento do Estado Social no século XX e na mudança das estruturas da desigualdade (PIKETTY, 2014).

Fala-se em tributação regressiva quando essa toma como base tributos indiretos, ou seja, aqueles que incidem sobre o consumo de bens, serviços e produção (ANSELMINI; BUFFON, 2018). Atingem, pois, "manifestações mediatas da capacidade contributiva, tributam a despesa, a transferências de bens ou outras manifestações indiretas da capacidade contributiva" (NABAIS, 2017, p. 61). Ou seja, a tributação indireta mantém o "anonimato" do sujeito passivo, enquanto, nos tributos diretos, considera-se o contribuinte individualmente (BALEEIRO, 2015), pois se "têm por pressuposto a própria existência duma pessoa, dum patrimônio ou dum rendimento" (NABAIS, 2017, p. 61).

Tributação progressiva e regressiva, tributos diretos e indiretos, ainda se relacionam à própria ideia democracia:

Atualmente, os contribuintes que mais renda têm são mais favorecidos pela tributação indireta. Como possuem mais renda, podem poupar e investir, deixando parcela de sua renda livre da tributação indireta. Os contribuintes com renda menor a utilizam integralmente para o consumo, estando submetidos aos impostos indiretos. Impostos indiretos estão ligados à aristocracia; impostos diretos, à democracia (KIRCHHOF, 2020, p. 534).

Hoje no Brasil, embora a Constituição tenha prestigiado a progressividade no Art. 153, § $2^{\circ}$, I (SCHOUERI, 2017), a tributação é muito mais regressiva, uma vez que há uma concentração grande na tributação sobre o consumo e a produção, a qual chega até mesmo a minar a progressividade existente nos impostos diretos:

6 O Brasil, assim como os demais países em desenvolvimento, tributa mais o consumo do que a renda, já que a base de contribuintes-consumidores é maior que o da renda, é mais fácil de arrecadar, exigem menor sofisticação da administração tributária (pois se utilizam de bases físicas e não contábeis), e porque há uma resistência da elite à tributação sobre o patrimônio, a renda e as heranças. (SANDFORD, 2000, p. 67-116). 
A tributação indireta sobre o consumo e produção (ICMS, IPI, PIS, Cofins e Cide), por sua vez, foi responsável por aumentar a desigualdade de renda (Gini) em 4,7\% em 2009, ante efeito quase igual em 2003 , de $4,6 \%$. O caráter regressivo desse tipo de tributação que responde pela maior parte da arrecadação de impostos no Brasil - mais do que compensa o efeito progressivo dos impostos diretos - Imposto de Renda, contribuições previdenciárias, IPTU, IPVA e outros -, que, pelas alíquotas demasiadamente baixas e as isenções concedidas, reduziram a desigualdade em apenas $2,6 \%$ em 2009 e 1,9\% em 2003 (CARVALHO, 2018, p. 52).

A excessiva regressividade adotada soma-se à baixa tributação das rendas elevadas, de grandes patrimônios, $\mathrm{e}$ das heranças e doações, o que resulta em prejuízo para os mais pobres (ANSELMINI; BUFFON, 2018), injustamente mais tributados e com menores chances de mobilidade social:

É intuitivo que pessoas de baixa renda consomem, no próprio mês, tudo o que recebem; quanto maior a renda, maior o percentual desta que poderá ser destinado à poupança. Uma pessoa de altíssima renda, mesmo que consuma muito mais que aqueles de renda mais baixa, ainda assim terá baixo percentual de sua renda destinado ao consumo. Ou seja: para uma pessoa que receba um salário mínimo, por exemplo, possivelmente terá a totalidade de sua renda empregada no consumo. Se admitirmos que a tributação do consumo seja de $20 \%$, então se dirá que $20 \%$ da renda dessa pessoa foi destinada ao pagamento de tributos. Considere-se, agora, uma pessoa com renda de 100 salários mínimos. É razoável admitir que seu padrão de gastos seja muito mais elevado. Diga-se que 50 salários mínimos sejam seu gasto mensal. Se a alíquota do imposto permanece em $20 \%$, então se dirá que o imposto será de $20 \%$ sobre 50 salários mínimos (consumidos), o que equivale a $10 \%$ de sua renda total de 100 salários mínimos. Ou seja: no exemplo, o contribuinte com 1 salário mínimo destinou $20 \%$ de sua renda ao pagamento de impostos, enquanto o outro, que ganha 100 salários mínimos, destinou $10 \%$ de sua renda ao mesmo fim. Aí se evidencia o caráter regressivo da tributação do consumo (SCHOUERI, 2017, p. 427-428).

No Brasil, embora tenha havido um aumento contínuo da carga tributária bruta nos últimos anos, ao contrapor este dado com a base de incidência, é revelado um cenário de exacerbação da regressividade, que contribui para a permanência e até aprofundamento das desigualdades sociais (FEITOSA; OLIVEIRA, 2018), marca registrada do país.

Outro fator que contribui para agravar o atual panorama de regressividade é o fato de que, além das populações mais pobres contribuírem mais para o sustento do Estado, não há um investimento significativo em políticas públicas que garantam seus direitos básicos (ANSELMINI; BUFFON, 2018). E sabe-se que a redução das desigualdades - objetivo constitucionalmente definido - também é enfrentada de maneira eficiente quando os serviços públicos disponíveis são de qualidade (CARVALHO, 2018).

Em estudo publicado pelo Instituto de Pesquisa Econômica Aplicada (IPEA) que analisou dados da Pesquisa de Orçamento Familiar (POF) do Instituto Brasileiro de Geografia e Estatística (IBGE) nos anos de 2002/2003 e de 2008/2009, e em relação à carga tributária total, demonstrou-se que, no sopesamento entre a suposta progressividade da tributação direta no Brasil e da tributação indireta regressiva, o perfil da tributação no país é regressivo. Nos $10 \%$ mais pobres, a tributação total atinge cerca de $30 \%$ da renda, enquanto nos $10 \%$ mais ricos representa apenas $12 \%$ (SILVEIRA, 2011).

A Receita Federa do Brasil, em junho do corrente ano de 2020, publicou os números do Imposto de Renda sobre a Pessoa Física (IRPF) do ano-calendário de 2018. Neste relatório, fica evidente que, ainda que possua faixas de rendas com alíquotas progressivas, o IRPF é insuficiente, nos moldes atuais, para promover justiça fiscal. O relatório aponta que, dentre os rendimentos - frise-se - declarados, há um imenso montante de 327, 91 bilhões correspondente a lucros e dividendos que são isentos da tributação por meio do IRPF (RECEITA FEDERAL, 2020). Além da evidente perda de arrecadação, elimina-se uma oportunidade de promover a distribuição de renda, pois, na esteira de Tipke e Lang, a progressividade do imposto de renda tem sua justificativa extraída, sobretudo, da ideia de redistribuição (justiça redistributiva) (TIPKE; LANG, 2008).

Assim, na esteira do que se compreende por redistribuição fiscal nos Estados contemporâneos - que não se limita apenas a transferências diretas, como programas de renda mínima e aposentadorias - e das despesas financiadas diretamente pelo Estado (PIKETTY, 2015), como é o caso do SUS, no Brasil, mas que se realiza também através dos tributos, o Brasil vem falhando em promover a efetiva redistribuição via sistema tributário. 
Logo, a regressividade da tributação é um fator a ser enfrentado, tendo em vista a construção de um sistema tributário mais justo e em consonância com os objetivos da República propugnados na Constituição, uma vez que um dos objetivos maiores - a redução das desigualdades - é obstado por esta. A progressividade, por seu turno, pode ser considerada, inclusive, como uma forma republicana de se cobrar impostos, uma vez que esta se fundamenta na isonomia (SCAFF, 2008).

A presente realidade colide frontalmente como texto constitucional e o que seria um padrão ideal de moralidade tributária por parte do Estado. Esta deve, pois, consistir no atendimento aos valores dos direitos constitucionais e alcançar a justiça através de uma distribuição igualitária da carga tributária tendo como parâmetro nesse desiderato a capacidade contributiva (TIPKE, 2012). E, sendo objetivo do ordenamento jurídico-tributário a distribuição de rendas (TORRES, 1998), a regressividade aponta para o sentido contrário, minando os objetivos constitucionais, em especial a redução das desigualdades.

Isto ocorre por uma opção política do legislador, em que são exemplos: a isenção do imposto de renda sobre lucros e dividendos distribuídos, a dedução dos juros sobre capital próprio (SANTIAGO, 2019), a reduzida tributação sobre heranças e doações, e a dependência da arrecadação em tributos indiretos. Enquanto a tributação progressiva constitui um instrumento de liberdade e democracia (FREITAS; BEVILACQUA, 2015), a realidade fiscal nacional caminha no sentido oposto de aumento da concentração de renda no topo da pirâmide social.

Nesse contexto, Branko Milanovic estudou os ganhos de renda dos mais ricos em duas situações distintas possíveis a partir de: (1) aumento da renda nacional, mantendo-se a distribuição inalterada; e (2) ampliação da distribuição de renda. Neste estudo, ele percebeu que os ganhos para os mais ricos tendem a ser desproporcionalmente mais altos em uma situação de crescimento econômico - ainda que baixo -no qual há manutenção do status da distribuição de renda, em comparação com os ganhos de em uma situação de crescimento econômico mais distribuído e diminuidor das desigualdades (MILANOVIC, 2016). Este dado ajuda a explicar a demagogia fiscal imperante e a opção política brasileira na regressividade tributária, e que contraria o próprio texto constitucional, contribuindo para a manutenção das desigualdades e da concentração de renda.

Tal cenário remonta, conforme aduz Júlio Cesar Santigo - com esteio em Ricardo Lobo Torres -, ao caráter individualista do liberalismo, em que o poder de tributar consubstancia-se no poder de destruir; no caso, os destruídos são os sub-representados nos espaços de poder (SANTIAGO, 2018).

\section{Conclusão}

Evidente é a deficiência da moral tributária do Estado brasileiro, o qual privilegia uma tributação regressiva em detrimento da capacidade contributiva, em descompasso com o desenho constitucional introduzido pela Constituição Cidadã. Do mesmo modo, é essa moral deficiente uma das principais responsáveis por uma tributação que favorece a concentração de renda e inviabiliza a redução das históricas e crescentes desigualdades sociais no país. É verdade que é impossível contentar a todos em uma sociedade plural, visto que são muitas as concepções de justiça tributária existentes. Contudo, os privilegiados aceitam seus privilégios e os possuem como um direito (TIPKE, 2012). E o contribuinte comum, frequentemente contaminado pelo discurso populista da tributação elevada dissipada por um Estado perdulário (TIPKE, 2012), endossa esses argumentos, contribuindo para a manutenção das iniquidades existentes.

Isso ocorre, em grande medida, porque o discurso está aprisionado por uma demagogia fiscal, entendido como argumentos repetidos e aparentemente universais, mas que mascaram um projeto de poder de grupos de interesse hegemônicos.

No entanto, em um Estado Democrático e Social de Direito, a tributação deve ser, além de garante das receitas que sustentam a administração pública, uma forma de efetivar a forma de Estado constitucionalmente definida (PISCITELLI, 2011). No Brasil, contudo, a maneira como se encontra configurada acaba por transformar a distribuição de renda em algo quixotesco (CARVALHO, 2018) e, dessa forma, sabota a efetivação da forma de Estado prevista na Constituição.

A regressividade no Brasil demonstra ainda a quase inexistente cultura republicana no Brasil (SCAFF, 2008). Em que pese a forma republicana seja a escolhida desde o século XIX, a efetivação da isonomia ainda não se tornou uma realidade, inclusive no campo tributário, no qual a capacidade contributiva é por vezes colocada de lado e a regressividade ganha corpo. 
A tributação constitui um instrumento fundamental na persecução dos objetivos constitucionais (PISCITELLI, 2011), entre eles, a redução das desigualdades e a construção de uma sociedade livre e justa, conforme preconizado pelo Art. $3^{a}$ da Constituição. Por isso, o Estado deve ter a sua política tributária revestida de uma moralidade voltada à realização da justiça social (GRUPENMACHER, 2019), para romper com a demagogia fiscal imperante. Desse modo, cabe adotar como princípio fundamental a capacidade contributiva, bem como corrigir a regressividade imperante de maneira a permitir a construção de uma tributação justa e capaz de cooperar na consecução desses objetivos constitucionais, em especial, na redução das desigualdades e na efetivação dos direitos fundamentais como expressão última da moralidade tributária

\section{Referências}

ADAMS, Charles. For good and evil: the impact of taxes on the course of civilization. 2. ed. New York: Madison, 1999.

ANSELMINI, Priscila; BUFFON, Marciano. Tributação como instrumento de redução das desigualdades no Brasil. Revista do Direito Público, Londrina, v. 13, n. 1, p. 226-258, abr. 2018.

BALEEIRO, Aliomar. Uma introdução à ciência das finanças. Atualizado por Hugo de Brito Machado Segundo. Rio de Janeiro: Forense, 2015.

CARVALHO, Laura. Valsa brasileira: do boom ao caos econômico. São Paulo: Todavia, 2018.

COMPARATO, Fábio Konder. Ensaio sobre o juízo de constitucionalidade de políticas públicas. Revista de Informação Legislativa, Brasília, v. 35, n. 138, p. 39-48, jun. 1998. Disponível em: http://www2.senado.leg.br/ bdsf/handle/id/364. Acesso em: 10 jun. 2020.

CORREIA NETO, Celso de Barros. 0 avesso do tributo: incentivos e renúncias fiscais no direito brasileiro. 2016. Tese (Doutorado em Direito) - Departamento de Direito Econômico, Financeiro e Tributário, Universidade de São Paulo, São Paulo, 2016. Disponível em: https://teses.usp.br/teses/disponiveis/2/2133/tde-15082013084732/pt-br.php. Acesso em: 10 jun. 2020.

CORREIA NETO, Celso de Barros. Os impostos e o Estado de Direito. São Paulo: Almedina, 2017.

COSTA, Regina Helena. Princípio da capacidade contributiva. São Paulo: Malheiros Editores, 1993.

DE PAULA, Daniel Giotti. Planejamento tributário e ética: a construção de um dever geral de combate a práticas abusivas. In: CAMPOS, Carlos Alexandre de Azevedo et al. (org.). Direitos fundamentais e estado fiscal: estudos em homenagem ao Professor Ricardo Lobo Torres. Salvador: Juspodivm, 2019. p. 727-742.

FEITOSA, Raymundo Juliano Rego; OLIVEIRA, Gustavo Henrique Maciel de. Federalismo fiscal e desigualdades regionais. In: DANTAS, José André Wanderley; ROSENBLATT, Paulo. Direito tributário: os 30 anos do Sistema Tributário Nacional na Constituição: estudos em homenagem a Ricardo Lobo Torres. Recife: Edição dos Organizadores, 2018. p. 172-193.

FREITAS, Leonardo Buissa; BEVILACQUA, Lucas. Progressividade na tributação sobre a renda com vistas à justiça fiscal e social. Interesse Público, Belo Horizonte, v. 17, n. 93, p. 87-106, 2015. Disponível em: http:// webcache.googleusercontent.com/search?q=cache:vTXYsjYGnLMJ:professor.pucgoias.edu.br/SiteDocente/ admin/arquivosUpload/18700/material/Artigo\%2520Buissa\%2520e\%2520Bevilacqua\%2520ProgressividdTri buta\%25C3\%25A7\%25C3\%25A3oSobre\%2520a\%2520Renda. pdf +\&cd=1\&hl=pt-BR\&ct=clnk\&gl=br. Acesso em: 10 jun. 2020.

GALLO, Franco. Las razones del fisco: ética y justicia em los tributos. Madrid: Marcial Pons, 2011.

GRUPENMACHER, Betina Treiger. Moralidade e capacidade contributiva. In: CAMPOS, Carlos Alexandre de Azevedo; OLIVEIRA, Gustavo da Gama Vital de; MACEDO, Marco Antonio Ferreira. Direitos fundamentais e estado fiscal: estudos em homenagem ao Professor Ricardo Lobo Torres. Salvador: Juspodivm, 2019. p. 469-483. 
HOLMES, Stephen; SUSTEIN, Cass R. The cost of rights: why liberty depends on taxes. New York: Norton, 1999.

KIRCHHOF, Paul. A ética da justiça fiscal. Tradução: Pedro Adamy. Revista Direito Tributário Atual, São Paulo, n. 44, p. 525-544, $1^{\circ}$ semestre 2020. Disponível em: https://ibdt.org.br/RDTA/wp-content/ uploads/2020/05/paul-e-pedro.pdf. Acesso em: 12 jul. 2020.

KÖCHE, Rafael; BUFFON, Marciano. Economia, ética e tributação: dos fundamentos da desigualdade. Revista Brasileira de Políticas Públicas, Brasília, v. 5, n. 1, p. 76-92, 2015.

MACHADO, Hugo de Brito. Os princípios jurídicos da tributação na Constituição de 1988. São Paulo: Editora Revista dos Tribunais, 1994.

MACHADO, Raquel Cavalcanti Ramos. Competência tributária: entre a rigidez do sistema e a atualização interpretativa. São Paulo: Malheiros Editores, 2014.

MARTINS, Ives Gandra da Silva. O princípio da moralidade no direito tributário. In: MARTINS, Ives Gandra da Silva (coord.). $O$ princípio da moralidade no direito tributário. São Paulo: Editora Revista dos Tribunais, 1996. p. 17-37.

MILANOVIC, Branko. Why might the rich be indifferent to income growth of their own countries? Economics Letters, [S.I.], v. 147, p. 108-111, out. 2016. DOI: http://dx.doi.org/10.1016/j.econlet.2016.08.027. Disponível em: https://stonecenter.gc.cuny.edu/files/2016/10/milanovic-why-might-the-rich-be-indifferent-to-income-growth-oftheir-own-countries-2016.pdf. Acesso em: 20 jun. 2020.

MURPHY, Richard. The joy of tax. London: Transworld Publishers, 2015.

NABAIS, José Casalta. Direito fiscal. Coimbra: Almeidina, 2017.

NABAIS, José Casalta. Por um estado fiscal suportável: estudos de direito fiscal. Coimbra: Almedina, 2008. v. 2.

OXFAM BRASIL. A distância que nos une: um retrato das desigualdades brasileiras. São Paulo: OXFAM Brasil, 2017. Disponível em: https://www.oxfam.org.br/um-retrato-das-desigualdades-brasileiras/a-distancia-quenos-une/. Acesso em: 07 jun. 2018.

OXFAM BRASIL. País Estagnado: um retrato das desigualdades brasileiras 2018. São Paulo: OXFAM Brasil, 2018. Disponível em: https://www.oxfam.org.br/um-retrato-das-desigualdades-brasileiras/pais-estagnado/. Acesso em: 10 jun. 2020.

PASSOS, Luana; GUEDES, Dyeggo Rocha; SILVEIRA, Fernando Gaiger. Justiça fiscal no Brasil: que caminhos trilhar? In: FAGNANI, Eduardo (org.). A reforma tributária necessária: diagnóstico e premissas. Brasília: ANFIP: FENAFISCO; São Paulo: Plataforma Política Social, 2018. p. 93-111.

PIKETTY, Thomas. O capital no século XXI. Rio de Janeiro: Intrínseca, 2014.

PIKETTY, Thomas. A economia da desigualdade. Rio de Janeiro: Intrínseca, 2015.

PISCITELLI, Tathiane dos Santos. Argumentando pelas consequências no direito tributário. São Paulo: Noeses, 2011.

BRASIL. Ministério da Economia. Receita Federal. Grandes números: IRPF - Ano-Calendário 2018, Exercício 2019. Brasília: Ministério da Economia: Receita Federal, 2020. Disponível em: http://receita.economia.gov.br/ dados/receitadata/estudos-e-tributarios-eaduaneiros/estudos-eestatisticas/11-08-2014-grandes-numeros-dirpf/ grandes-numeros-irpf-2018-2019-completo.pdf. Acesso em: 15 jul. 2020.

RIBEIRO, Maria de Fátima; GESTEIRO, Natália Paludetto. A busca da cidadania fiscal no desenvolvimento econômico: função social do tributo. In: SANTOS, António Carlos dos et al. (org.). Fiscalidade: outros olhares. Porto: Vida Económica, 2013. p. 201-216. 
ROSENBLATT, Paulo. A revolução fiscal de Pernambuco de 1817. In: CAULA, César; CONTINENTINO, Marcelo Casseb; ROSENBLATT, Paulo. Bicentenário da Lei Orgânica da Revolução de 1817. Belo Horizonte: Fórum, 2018. p. 331-352.

SÁ, Cristina; MARTINS, António. A moralidade fiscal e as obrigações tributárias. In: SANTOS, António Carlos dos; LOPES, Cidália Maria da Mota. Fiscalidade: outros olhares. Porto: Vida Económica, 2013. p. 245-266.

SANCHES, Saldanha J. L. Justiça fiscal. Lisboa: Relógio D’Água: Fundação Francisco Manuel dos Santos, 2010.

SANDFORD, Cedric. Why tax systems differ. Bath, ENG.: Fiscal Publications, 2000.

SANTIAGO, Julio Cesar. O poder tributário para o século XXI. Revista de Finanças Públicas, Tributação e Desenvolvimento, Rio de Janeiro, v. 6, n. 6, p. 1-17, 6 jun. 2018. DOI: http://dx.doi.org/10.12957/ rfptd.2018.34736. Disponível em: https://www.e-publicacoes.uerj.br/index.php/rfptd/article/view/34736. Acesso em: 11 jun. 2020.

SANTIAGO, Julio Cesar. Solidariedade: como legitimar a tributação?. Rio de Janeiro: Lumen Juris, 2019. SCAFF, Fernando Facury. República, tributação, finanças. Revista do Instituto de Hermenêutica Jurídica, Porto Alegre, v.1, n.6, p. 79-104, 2008.

SCHOUERI, Luis Eduardo. Direito tributário. São Paulo: Saraiva, 2017.

SILVEIRA, Fernando Gaiger et al. Equidade fiscal no Brasil: impactos distributivos da tributação e do gasto social. Brasília: Comunicados do IPEA, 2011. Disponível em: http://repositorio.ipea.gov.br/handle/11058/5207. Acesso: 10 jun. 2020.

SILVESTRE, Ana Carolina de Faria. O contribuinte e o fisco: ou pela necessária assunção das emoções no âmbito das relações entre o contribuinte e o fisco. In: SANTOS, António Carlos dos et al. Fiscalidade: outros olhares. Porto: Vida Económica, 2013. p. 331-352.

TORRES, Ricardo Lobo. Ética e justiça tributária. In: SCHOUERI, Luís Eduardo; ZILVETI, Fernando Aurélio (org.). Direito tributário: estudos em Homenagem a Brandão Machado. São Paulo: Dialética, 1998. p. 173-196.

TORRES, Ricardo Lobo. Legalidade tributária e riscos sociais. Revista Dialética de Direito Tributário, São Paulo, n. 59, p. 95-112, 2000.

TIPKE, Klaus. Moral tributária do Estado e dos contribuintes. Porto Alegre: Sérgio Antonio Fabris, 2012. TORRES, Ricardo Lobo. Tratado de direito constitucional financeiro e tributário. Rio de Janeiro: Renovar, 2005. v. 2.

UCKMAR, Victor. Principios comunes del derecho constitucional tributário. Bogotá: Editorial Themis S.A., 2002.

VALIM, Rafael. A atividade administrativa de fomento no contexto da Covid-19: em defesa da renda básica universal. In: WARDE, Walfrido; VALIM, Rafael. As consequências da Covid-19 no direito brasileiro. São Paulo: Contracorrente, 2020. p. 67-77.

YOURCENAR, Marguerite. Memórias de Adriano. Rio de Janeiro: Nova Fronteira, 2019.

Recebido em: 27. 07. 2020

Aceito em: 20. 09. 2021 